\title{
ESTUDO DO USUÁRIO NAS BIBLIOTECAS DA UNIVERSIDADE DE CAXIAS DO SUL
}

Resumo: $O$ trabalho apresenta os resultados do estudo de usuário realizado pelo Sistema de Bibliotecas da Universidade de Caxias do Sul através do método de pesquisa quantitativa aplicada à comunidade acadêmica da instituição. Esse estudo teve como objetivo mensurar o grau de satisfação dos usuários das bibliotecas que fazem parte, bem como analisar e suprir suas reais necessidades na utilização do espaço físico e serviços oferecidos. Também, por meio dos resultados obtidos, pode-se traçar um perfil do usuário, verificando alguns hábitos para a recuperação da informação, além de identificar e compreender suas necessidades. Quanto à metodologia aplicada, esse estudo baseou-se na elaboração de um questionário eletrônico contendo 18 questões de múltipla escolha. Após, esse questionário foi disponibilizado por meio de um link gerado pelo Google Formulários e enviado por e-mail para a comunidade acadêmica da instituição. Quanto ao fechamento do questionário, houve um espaço de sugestões para servir como melhoria aos serviços oferecidos. A maior parte dos usuários declarou que encontra, na maioria das vezes, o material que procura e qualifica os serviços da biblioteca de forma positiva. Estudo de usuários como esse em bibliotecas são relevantes para mensurar o grau de satisfação, avaliar os serviços das bibliotecas e conhecer o perfil do público a quem se destina.

Palavras-chave: Estudo de usuário. Biblioteca universitária. Necessidades de informação. Universidade de Caxias do Sul. Sistema de Bibliotecas.

\author{
Michele Marques Baptista \\ Mestre em Letras, Cultura e Regionalidade \\ Universidade de Caxias do Sul \\ Administrativa do Sistema de Bibliotecas \\ mmbaptis@ucs.br \\ Márcia Gonçalves \\ Especialista em Gestão de Pessoas pela \\ UCS \\ Universidade de Caxias do Sul \\ Setor de Atendimento da Biblioteca Central \\ da UCS \\ msgoncal@ucs.br
}

\section{STUDY OF THE USER IN THE LIBRARIES OF THE UNIVERSITY OF CAXIAS DO SUL}

\begin{abstract}
The work presents the results of the user study carried out by the Library System of the University of Caxias do Sul through the method of quantitative research applied to the academic community of the institution. This study aimed to measure the degree of satisfaction of the users of the libraries that are part, as well as to analyze and supply their real needs in the use of the physical space and services offered. Also, through the results obtained, it is possible to draw a profile of the user, checking some habits for information retrieval, as well as identifying and understanding their needs. As for the applied methodology, this study was based on the elaboration of an electronic questionnaire containing 18 multiple choice questions. Afterwards, this questionnaire was made available through a link generated by Google Forms and sent by e-mail to the institution's academic community. As for the closing of the questionnaire, there was a space of suggestions to serve as an improvement to the services offered. Most users have stated that they often find the material they find and qualify for library services in a positive way. Study of users like this in libraries are relevant to measure the degree of satisfaction, evaluate library services and know the profile of the audience for whom it is intended.
\end{abstract}

Keywords: User study. University library. Information needs. University of Caxias do Sul. Library System. 


\section{INTRODUÇÃO}

Nos dias atuais, ainda são abordados tópicos e dados relacionados ao estudo de usuários em bibliotecas. Tal assunto é muito relevante em todos os sentidos nas unidades de informação, pois possibilita o conhecimento de algumas necessidades informacionais e, também, permite analisar, por meio de pesquisas, a satisfação dos usuários quanto aos serviços oferecidos.

A partir de estudos realizados com os usuários ou com a comunidade que frequenta determinada biblioteca, é possível objetivar quais as dúvidas e incertezas sobre os serviços informacionais disponibilizados, tais como o acesso aos itens do acervo, o uso e compartilhamento de informações, as informações em bases de dados e livros digitais existentes, etc. Com isso, consegue-se fazer um mapeamento de como os usuários utilizam determinadas fontes informacionais para resolverem suas questões. São estudos "necessários também para ajudar a biblioteca na previsão da demanda ou da mudança da demanda de seus produtos e serviços, permitindo que sejam alocados os recursos necessários na época adequada". (FIGUEIREDO, 1994, p. 7).

De acordo com Gonçalves (2013), os problemas relacionados à informação e às necessidades informacionais devem ser tratados com o profissional da informação. É tarefa dele propiciar melhores condições e oferecer um ambiente com serviços adequados aos usuários. Figueiredo (1979) também diz que todos os tipos de serviços oferecidos, bem como as estruturas organizacionais, os profissionais que fazem parte, os recursos disponibilizados, são fatores que devem ser considerados na fase inicial de uma biblioteca e precisam ser revistos e avaliados de acordo com estudos realizados para que a biblioteca cumpra sua missão.

Por meio de estudos de usuários desenvolvidos em bibliotecas, pode-se verificar como, por que e para qual fim os usuários utilizam a informação e quais os fatores a serem melhorados. Sendo assim, esse estudo teve como principal objetivo avaliar os serviços de referência oferecidos pelo Sistema de Bibliotecas da Universidade de Caxias do Sul1, traçando um perfil de usuário, bem como verificando a satisfação, por meio de seus hábitos, para recuperar a informação.

\footnotetext{
${ }^{1}$ Será utilizada a sigla SiBUCS no texto para identificar o Sistema de Bibliotecas da Universidade de Caxias do Sul. 


\section{A BIBLIOTECA UNIVERSITÁRIA E O ESTUDO DE USUÁRIO}

A Biblioteca Universitária é um órgão que promove apoio informacional às atividades de ensino, pesquisa e extensão. Para disseminar de forma mais eficaz as informações e os serviços prestados pela biblioteca, é preciso que se conheça o usuário.

Os estudos de usuários vêm sendo aplicados desde a década de 30, surgindo a partir da investigação de como as pessoas liam. Estudar as necessidades do usuário possibilita desenvolver procedimentos mais adequados para agilizar e atender a busca da informação, pois, de acordo com Figueiredo (1994, p. 7), “estudos dos usuários são investigações que se faz para saber o que os indivíduos precisam em matéria de informação”. É por meio desses estudos que o bibliotecário poderá gerir melhor os serviços oferecidos pela biblioteca e inovar em alguns procedimentos. A autora aponta, ainda, para a importância de encorajar os usuários "a tornar suas necessidades conhecidas e ao mesmo tempo, a assumirem alguma responsabilidade para que estas necessidades de informação sejam atendidas pelas bibliotecas ou centros de informação". (FIGUEIREDO, 1979, p. 79).

Conforme a ideia de Casarin (2014), o ambiente empresarial é complexo quando o contexto de atuação é competitivo, influenciando, assim, no comportamento das pessoas o que, por sua vez, afeta as atividades desempenhadas. Já Gonçalves (2013, p. 134) diz que o profissional da informação é o responsável por buscar dados relevantes quanto às necessidades informacionais dos usuários. Para a autora, "o profissional que lida com a informação deve atuar como um intermediário entre os sistemas e os públicos aos quais se destinam”.

Para que se possa entender o comportamento dos usuários do SiBUCS, é necessário conhecer a cultura organizacional da empresa/instituição. Nesse caso, objetiva-se, como meta de estudo, não somente o comportamento organizacional, mas também o comportamento informacional que é resultado da cultura e comunicação. A cultura e a comunicação, de acordo com Gonçalves (2014), influenciam no comportamento informacional e se ajustam às características de estrutura, do ambiente e dos fluxos existentes.

Outrossim, Leitão (2005) diz que, embora as bibliotecas sejam consideradas prestadoras de serviço, assim mesmo para o usuário não fica claro e o mesmo se torna um questionador sobre os serviços oferecidos pelas bibliotecas. A autora ainda afirma que, 
Todos os profissionais que atuam em sistemas de informação necessitam estar preparados para esse novo paradigma, que envolve um radical abandono da ideia de prestação de serviço como um procedimento pronto, acabado, de tal forma que suas regras, procedimentos e padrões não necessitam ser avaliados e modificados continuamente. Deve haver uma tomada de consciência do que representa a informação para a sociedade (LEITÃO, 2005, p. 20).

Muitos usuários desconhecem os recursos disponíveis e fontes de informação nas bibliotecas devido ao baixo marketing ou divulgação dos serviços, por isso a necessidade de, além da aplicação de um estudo, fornecer informações relevantes para conhecimento desses recursos e fontes. Como afirma uma das cinco leis2 de Ranganathan, divulgadas desde o ano de 1931, "a Biblioteca é um organismo em crescimento". Assim, analisando essa afirmação, pode-se perceber que as bibliotecas estão sempre em busca da evolução dos seus serviços/produtos, voltados a suprir as necessidades dos usuários.

\section{A DISSEMINAÇÃO DA INFORMAÇÃO NO MEIO ACADÊMICO}

Várias mudanças vêm transformando rapidamente a vida acadêmica nas universidades, especialmente nos últimos anos. Apesar das Tecnologias de Informação e Comunicação (TICs) desenvolvidas para facilitar o cotidiano dos usuários em bibliotecas, tais avanços estão interligados às mudanças socioeconômicas.

Pensar em reorganização de novos espaços e serviços em bibliotecas é um desafio. Através do tempo, a disseminação da informação e do conhecimento processa-se de modo acelerado. No meio acadêmico, por exemplo, a disseminação da informação acaba por ressaltar o aparecimento de bases virtuais e de livros eletrônicos. Nesse aspecto avançado das TICs e na realidade atual das bibliotecas, é indispensável que o usuário se adapte aos novos conhecimentos e serviços, porque o presente momento e, também, o futuro, estão exigindo um novo perfil de usuário, ou seja, aquele que sabe acessar, procurar e identificar uma grande quantidade de informações disponíveis em vários ambientes virtuais. Conforme Cunha (2006, p. 97),

\footnotetext{
${ }^{2}$ As cinco leis de Ranganathan: 1 - Livros são para usar; 2 - A cada leitor seu livro; 3 - A cada livro seu leitor; 4 - Poupe o tempo do leitor; 5 - A Biblioteca é um organismo em crescimento (SANTOS, 2015, p. 472). 
para além do modelo tradicional da simples recuperação da informação demandada pelo usuário, que nem sempre assegura a apropriação possível de transformá-la em conhecimento, hoje as bibliotecas voltam-se para a função de promoção do uso da informação em que se insere a estratégia de disseminação, com uma ação mais específica de levar a informação com rapidez e qualidade a partir do conhecimento da necessidade real dos usuários.

Além disso, corroborando com a citação acima, por gerar dúvidas e incertezas quanto aos produtos e serviços da biblioteca, a maioria dos usuários desconhece a que eles têm de direito. Existem várias formas de disseminação da informação, até mesmo por meio de uma conversa com os usuários enquanto eles acessam o catálogo. Descobrir se os usuários obtêm o que procuram pode ser bom ou ruim, vai depender da forma de conhecimento ou da abordagem. O objetivo é reconhecer que se trata de uma forma bastante complexa de comportamento e que as respostas dos usuários devem ser avaliadas e interpretadas garantindo a melhoria dos serviços. As bibliotecas passam a não serem mais vistas como somente um espaço de armazenamento de livros, mas se destacam como um local moderno e com serviços novos por meio de avançadas tecnologias.

\section{PROCEDIMENTOS METODOLÓGICOS}

O estudo teve o intuito de averiguar e conhecer as necessidades e expectativas dos usuários quanto aos serviços oferecidos pelo SiBUCS. Dentre estes serviços destacam-se: serviço de referência, acesso às bases de dados e livros eletrônicos, sistema de pesquisa no acervo, renovação de materiais, acessibilidade, oficinas de bases e de normas técnicas, bem como os demais serviços oferecidos pelo Sistema de Bibliotecas.

Como objetivos específicos delimitaram-se: avaliar os serviços de referência oferecidos pelo SiBUCS; traçar um perfil do usuário que frequenta as bibliotecas; aferir a satisfação dos usuários quanto aos serviços oferecidos; descobrir os hábitos dos usuários para recuperar a informação através dos serviços oferecidos; identificar e compreender as necessidades de informação dos usuários.

$\mathrm{Na}$ pesquisa, foi utilizado, como ferramenta, um formulário eletrônico de múltipla escolha disponibilizado através do Google Drive. Estruturado de forma objetiva, o formulário constou de 18 questões, com opções de respostas para cada uma delas. Somente a última 
questão oferecia um espaço para sugestões a fim de que o usuário colocasse o seu ponto de vista.

Os assuntos relevantes destacados no formulário e que tinham como objetivo facilitar a tabulação das respostas, bem como averiguar o que precisa melhorar, foram: conhecimento do perfil do usuário; biblioteca a que está vinculado e período de frequência; conhecimento dos canais de comunicação (site, redes sociais, etc.) e dos serviços oferecidos; hábitos de pesquisa.

O formulário foi enviado via e-mail à comunidade acadêmica ativa na instituição no período considerado de maior movimento nas bibliotecas e na Universidade. Os principais passos foram: envio do formulário para toda a comunidade acadêmica; data de término para recebimento dos formulários; tabulação dos dados; apresentação dos resultados.

\section{ANÁLISE E DISCUSSÃO DOS DADOS}

Para análise dos resultados, foram tabulados e analisados os dados referentes aos 949 usuários que responderam. A seguir, os gráficos que representam os dados das respostas às questões.

O Gráfico 1 refere-se à faixa etária dos usuários que frequentam o SiBUCS. Das opções, 53,5\% encontram-se na faixa dos 19 a 25 anos. Desta maneira, fica claro que os frequentadores da biblioteca são usuários jovens, seguidos de $24,2 \%$ de usuários entre os 26 e 35 anos.

Gráfico 1 - Faixa etária dos usuários 
1) Em qual faixa etária você se enquadra?

954 respostas

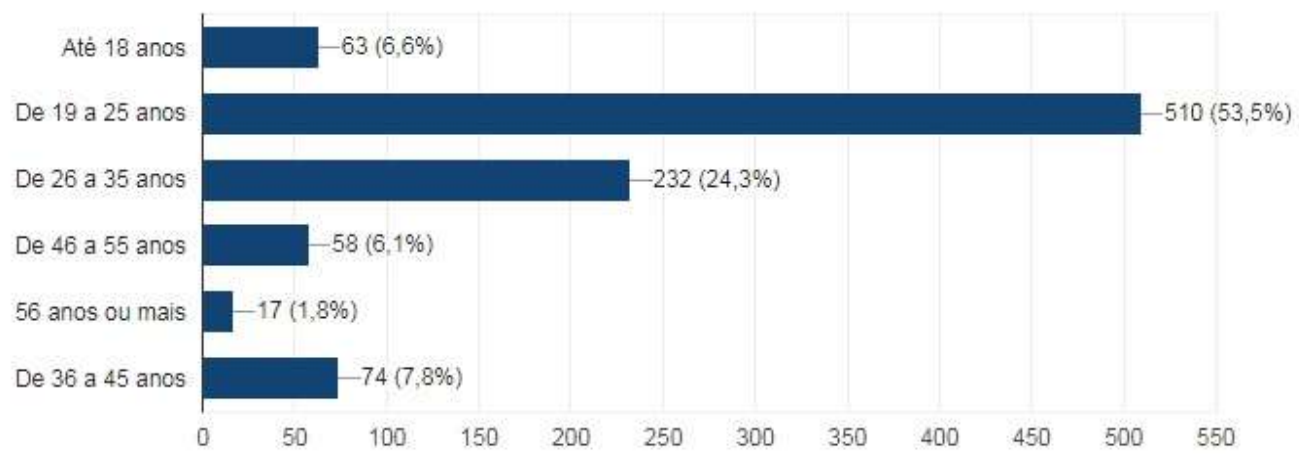

Fonte: SiBUCS (2017).

O Gráfico 2 buscava determinar o vínculo do estudante com a instituição.

Gráfico 2 - Vínculo do usuário com a instituição

2) Qual seu vínculo com a universidade?

954 respostas

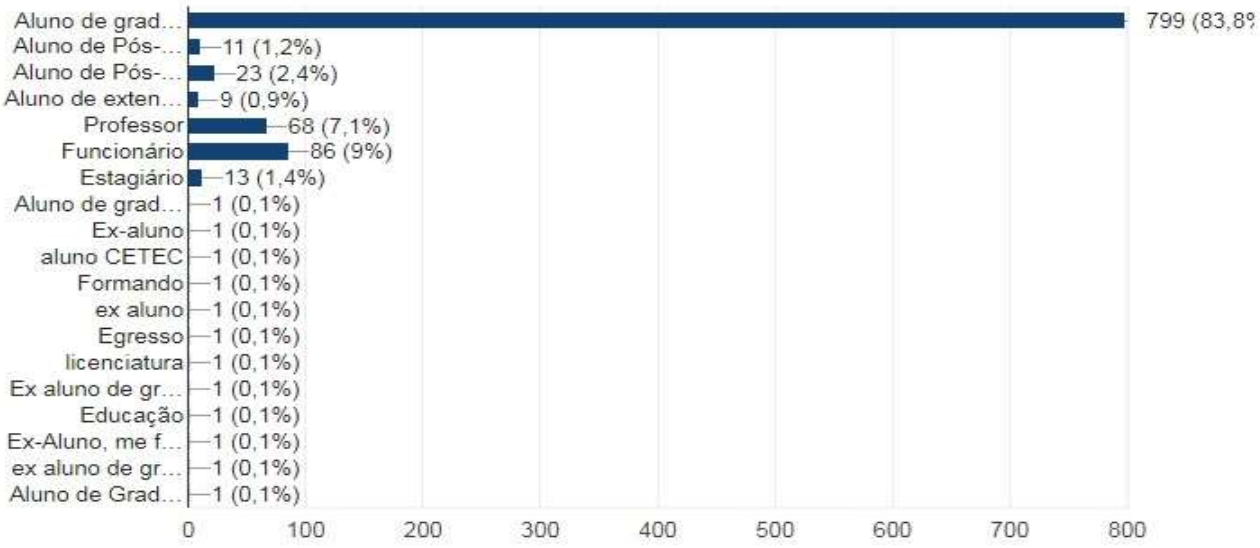

Fonte: SiBUCS (2017).

Percebe-se, por meio das respostas do Gráfico 2, que a maioria dos respondentes são alunos de graduação $(83,8 \%)$, sendo que os que mais participaram foram os alunos dos cursos de Direito, Administração de Empresas, Ciências Contábeis e Arquitetura e Urbanismo, de acordo com a questão 3, como apresenta a Figura 1.

Figura 1 - Curso de graduação a que o usuário pertence 


\begin{tabular}{|l|}
\hline 3) Se é aluno da graduação. Qual o seu curso? \\
786 respostas \\
Arquitetura e Urbanismo (28) \\
Engenharia Civil (21) \\
\hline Engenharia Mecânica (21) \\
\hline Psicologia (18) \\
\hline Jornalismo (16) \\
\hline Engenharia de Produção (15) \\
\hline Engenharia Química (13) \\
\hline Medicina Veterinária (13) \\
\hline Comércio internacional (13) \\
\hline DIREITo (12) \\
\hline Biblioteconomia (12) \\
\hline Pedagogia (10) \\
\hline
\end{tabular}

Fonte: SiBUCS (2017).

Já, por meio do Gráfico 4, consegue-se perceber que a maioria dos usuários frequenta mais o Campus-Sede em Caxias do Sul, onde se encontra localizada a Biblioteca Central.

Gráfico 4 - Campus Universitário a que o usuário pertence

4) Qual o seu Campus Universitário?

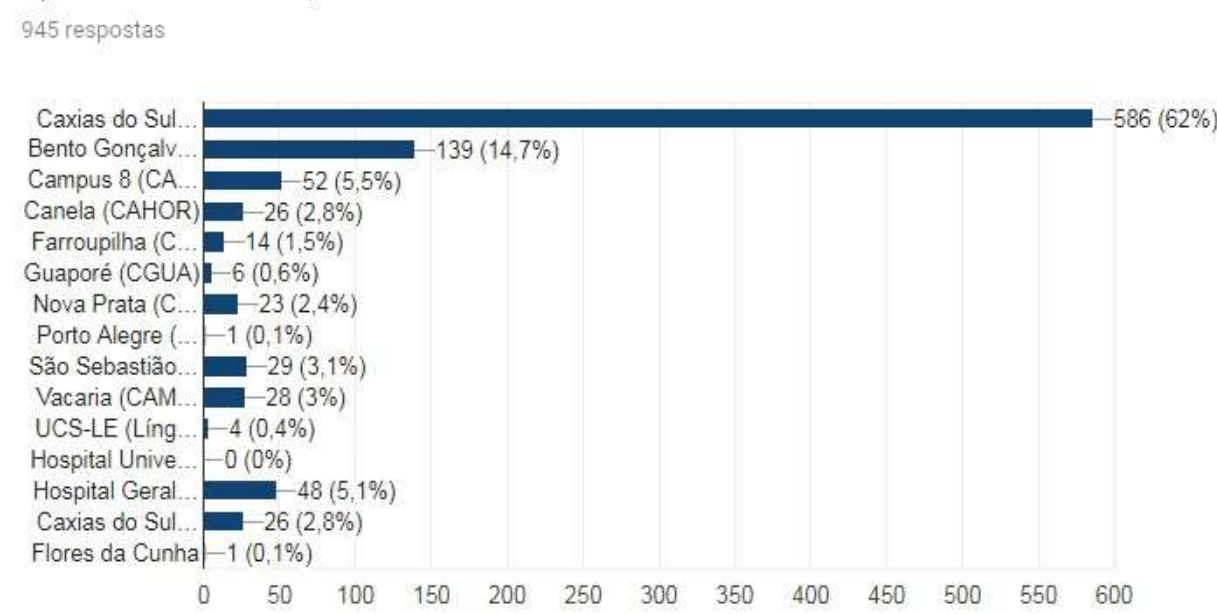

Fonte: SiBUCS (2017).

Quanto à frequência, no Gráfico 5 identifica-se, também, que 42,3\% afirmam frequentar a biblioteca semanalmente.

Gráfico 5 - Frequência de visita à biblioteca 
5) Com que frequência você visita a biblioteca?

954 respostas

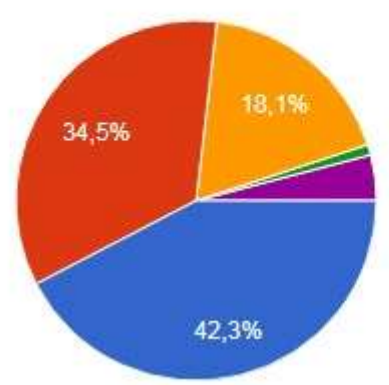

Semanaimente

Mensalmente

Raramente

- Não frequenta

- Diariamente

Fonte: SiBUCS(2017).

Ainda de acordo com os resultados obtidos, no que se refere ao horário de frequência, verifica-se, no Gráfico 6, que o turno vespertino vem em segundo lugar com 27,5\% de usuários. Esses dados referem-se a todas as bibliotecas que compõem o SiBUCS.

Gráfico 6 - Horário de frequência da biblioteca

6) Qual o horário que você frequenta a Biblioteca?

954 respostas

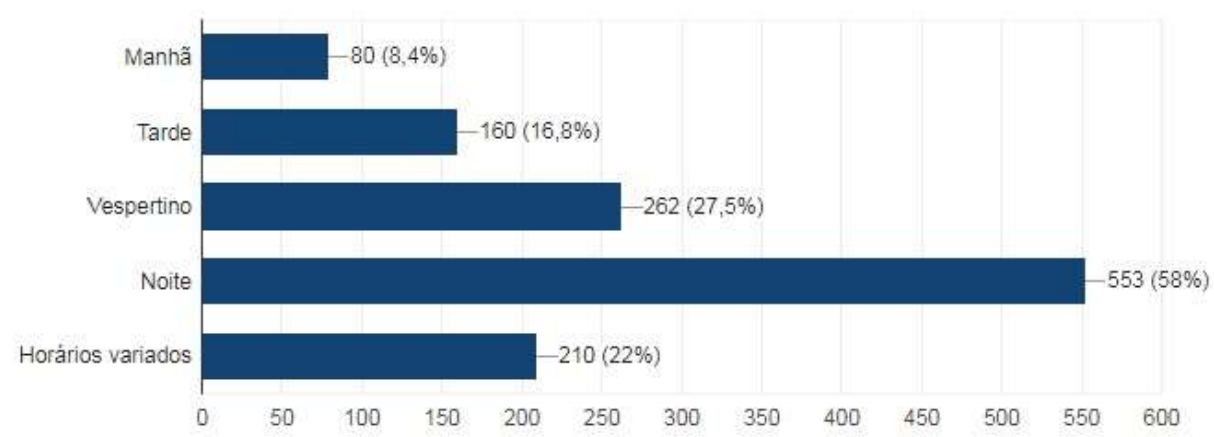

Fonte: SiBUCS (2017).

No Gráfico 7, constata-se que a maioria dos respondentes conhece os serviços oferecidos pelos Sistema de Bibliotecas da Universidade de Caxias do Sul. Isso reforça o quanto é importante a divulgação das informações, seja através do marketing da biblioteca, das redes sociais ou dos demais serviços oferecidos como as visitas orientadas. 
Gráfico 7 - Serviços oferecidos pela Biblioteca

7) Você conhece os serviços oferecidos pela Biblioteca?

954 respostas

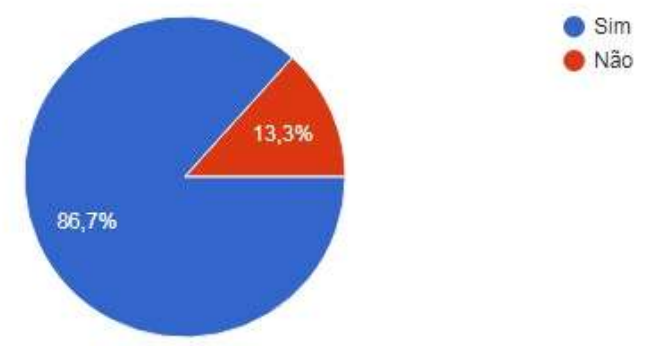

Fonte: SiBUCS (2017).

Os serviços oferecidos pelo SiBUCS são usados semanalmente por 46,4\% dos respondentes que dizem conhecer tais serviços, seguidos por $28,3 \%$ que informam usar os serviços mensalmente, como apresentam os dados do Gráfico 8.

Gráfico 8 - Frequência de uso dos serviços oferecidos

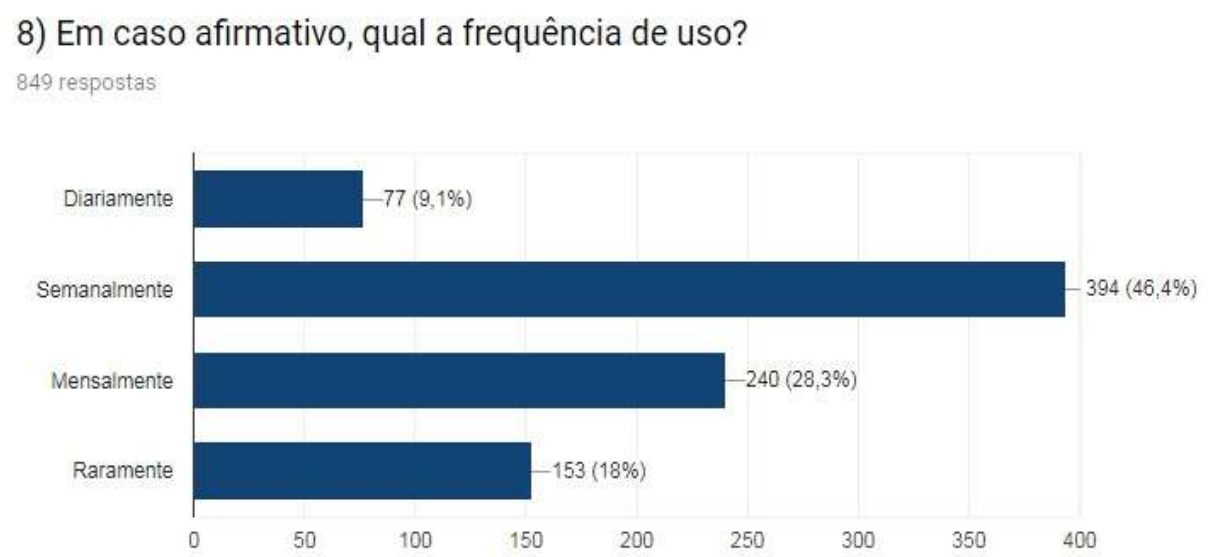

Fonte: SiBUCS (2017).

Quanto à questão sobre os canais de comunicação, mais de $80 \%$ conhecem o site do SiBUCS, seguido após o Facebook e Blog do Sistema. Apenas 11,4\% dos respondentes desconhecem os canais de comunicação do Sistema de Bibliotecas. Estes dados podem ser verificados no Gráfico 9.

Gráfico 9 - Canais de Comunicação da Biblioteca 
9) Quais os canais de comunicação da Biblioteca que você conhece? 954 respostas

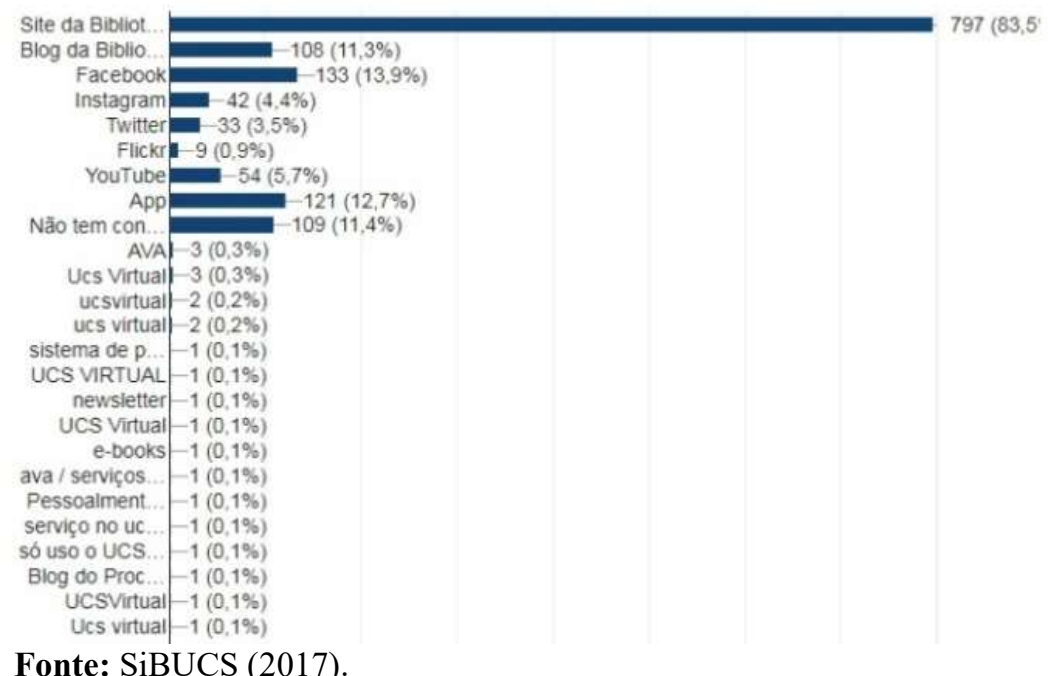

Fonte: SiBUCS (2017).

Mais de 92,6\% dos usuários afirma ter conhecimento dos serviços oferecidos pelo SiBUCS através do Ambiente Virtual de Aprendizagem - AVA, como apresenta o Gráfico 10.

Gráfico 10 - Conhecimento sobre os serviços oferecidos pela Biblioteca

10) Você tem conhecimento dos serviços oferecidos pela Biblioteca através: 954 respostas

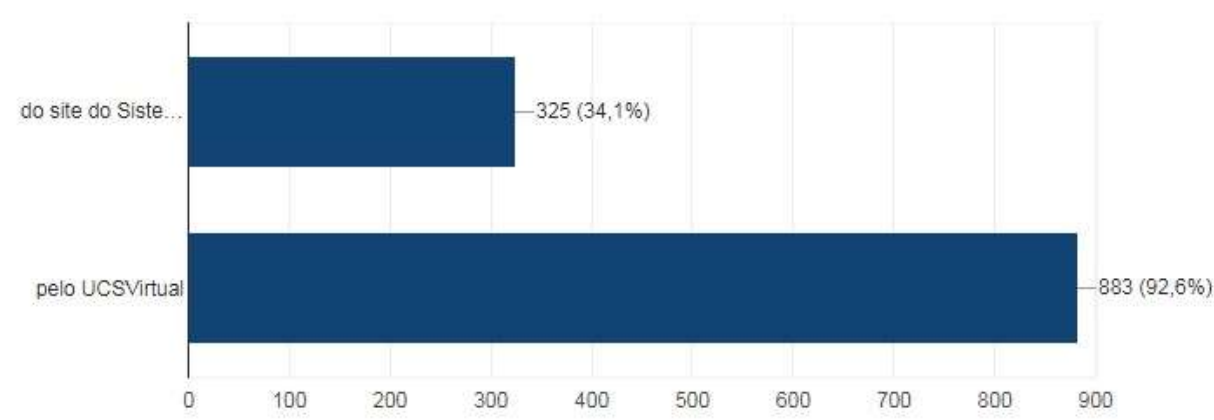

Fonte: SiBUCS (2017).

O Gráfico 11 indica que mais de $70 \%$ dos respondentes escolheram a consulta online ao catálogo e o acesso aos ebooks como os serviços mais utilizados, enquanto 46,5\% utilizam o acesso às bases de dados. 
Gráfico 11 - Serviços utilizados pelos usuários

11) Em caso AFIRMATIVO, assinale os serviços que você costuma utilizar. 923 respostas

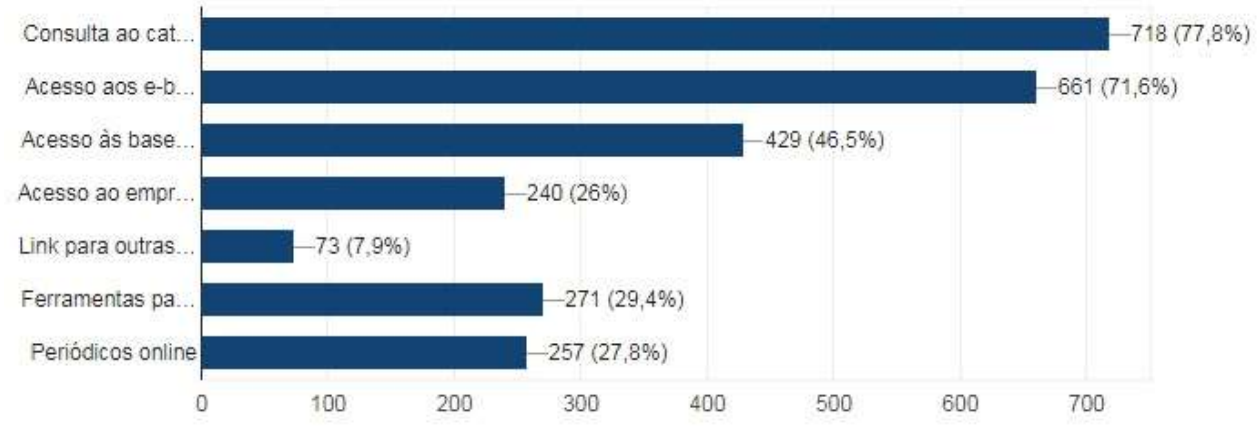

Fonte: SiBUCS (2017).

Quanto às bases de dados assinadas pela instituição, verifica-se, através do Gráfico 12, que a base de livros digitais "Minha Biblioteca" é a mais conhecida pelos usuários, seguida da base "BVU". As demais bases, por serem específicas de algumas áreas, são acessadas somente por alunos daquelas áreas.

Gráfico 12 - Conhecimento das bases de dados assinadas pela UCS

12) Das bases de dados assinadas pela UCS, quais você conhece e acessa?

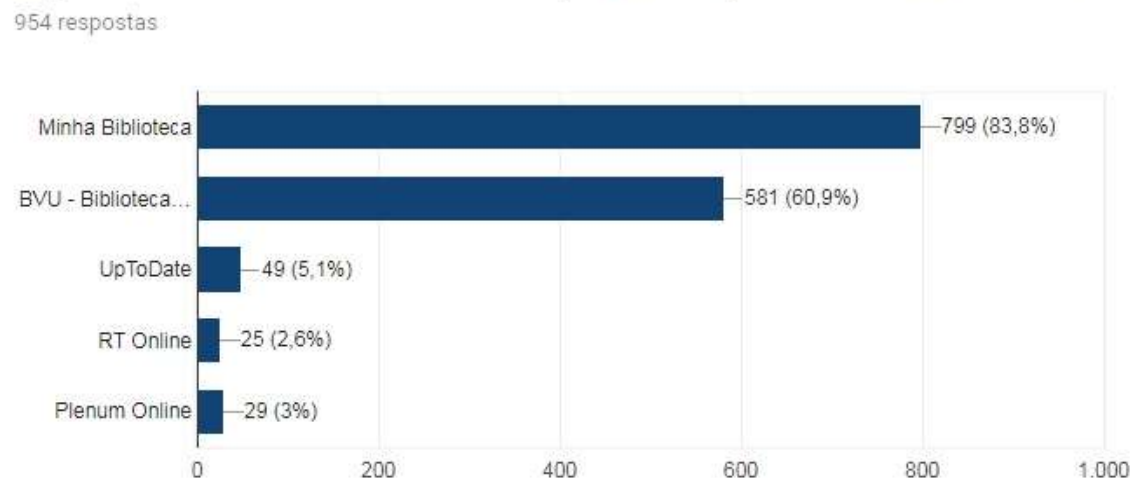

Fonte: SiBUCS (2017).

Considerando as bases de dados assinadas pela instituição, as que os usuários mais acessam são as bases de ebooks. Acima de $80 \%$ utilizam a base Minha Biblioteca e mais de $60 \%$ a Base Biblioteca Universitária Virtual - BVU da editora Pearson. Cerca de 70\% afirmam 
realizar suas buscas autonomamente, mas ainda há uma parcela que realiza a busca somente com auxílio dos colaboradores, de acordo com o Gráfico 13.

Gráfico 13 - Maneira de realizar buscas em bases de dados

13) Você prefere realizar buscas em bases de dados

954 respostas

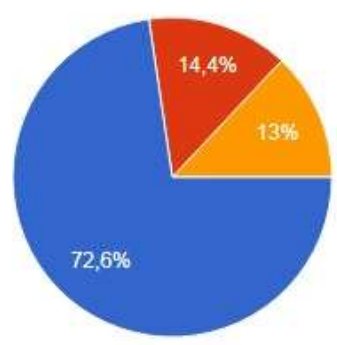

Com autonomia, sem ajuda dos

funcionários

Somente com ajuda dos funcionários

- Não realiza buscas em bases de

dados

Fonte: SiBUCS (2017).

A rapidez das informações e a quantidade de material disponível levam os usuários a optarem por esse tipo de pesquisa e serviço, como demonstra o Gráfico 14.

Gráfico 14 - Motivo para realizar busca em bases de dados

14) Qual o principal motivo que leva você a realizar a busca em bases de dados?

954 respostas
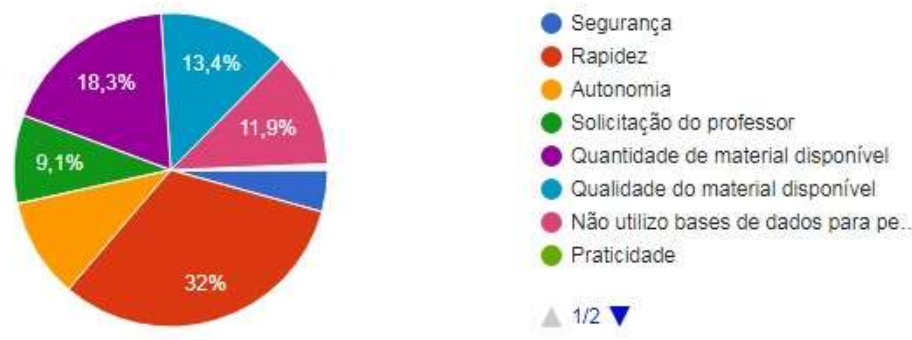

Fonte: SiBUCS (2017).

Sobre os serviços disponíveis no SiBUCS, os usuários acham mais importantes o catálogo online e o acesso às bases de dados ebooks e periódicos online, assim como oficinas de normalização em que são repassadas as informações sobre normalização de trabalhos acadêmicos, conforme o Gráfico 15. 
Gráfico 15 - Serviços considerados importantes

15) Dos serviços listados abaixo, assinale os que você considera importante.

954 respostas

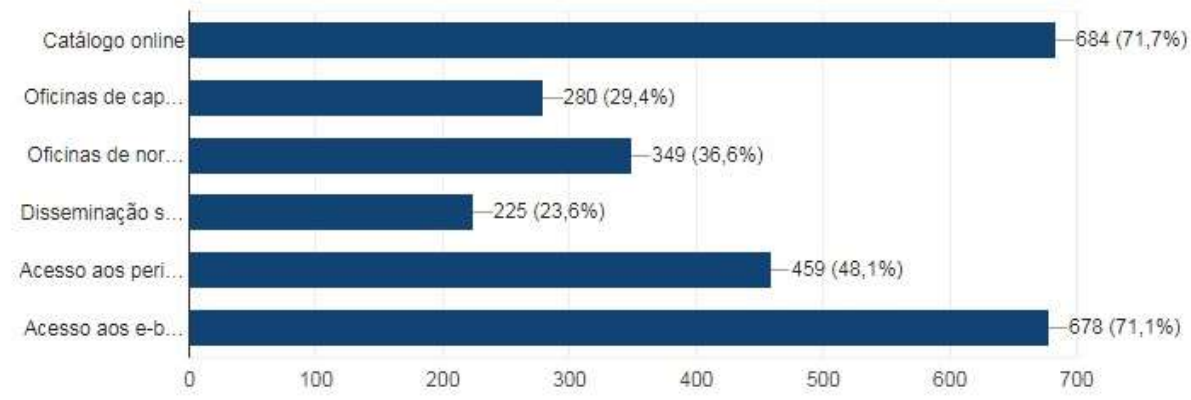

Fonte: SiBUCS (2017).

Uma das preocupações desse estudo era avaliar os serviços prestados pela equipe dos profissionais do SiBUCS no que se refere à disponibilidade dos materiais nas bibliotecas. A maioria dos usuários respondeu que encontram o material desejado disponível no acervo seja ele físico ou virtual. Destes, $11,4 \%$ alega que o material desejado está sempre emprestado. Nesse caso, conseguiu-se identificar os tipos e suportes mais retirados ou solicitados nas bibliotecas. Vale ressaltar que o usuário busca novas ferramentas por conta própria quando não encontra o material desejado. $\mathrm{O}$ estudo também nos mostra que $24,2 \%$ dos respondentes solicita ajuda ao bibliotecário quando não encontra o que procura, como apresentam os Gráficos 16 e 17.

Gráfico 16 - Acesso ao material da Biblioteca

16) Em geral, o material que você procura na biblioteca:

954 respostas

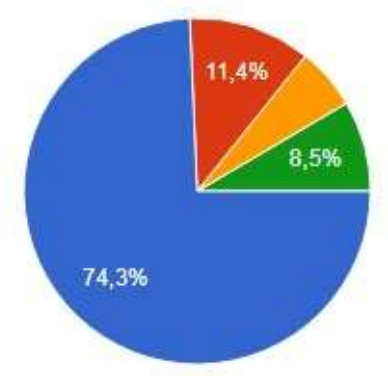

Está disponivel

Está emprestado

Encontra-se em outro Campus

- A biblioteca não possui

Fonte: SiBUCS (2017). 
Gráfico 17 - Alternativas de pesquisa

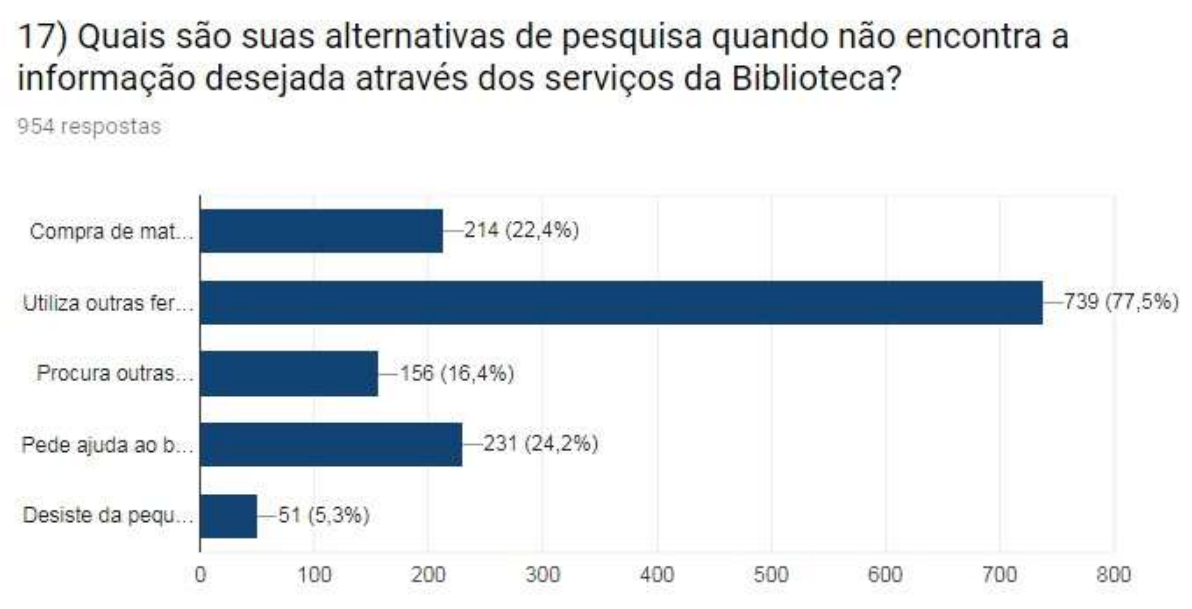

Fonte: SiBUCS (2017).

A última questão, de número 18, era aberta para sugestões. Das sugestões que foram enviadas, algumas são relevantes como: base de dados bastante ampla e de fácil acesso; melhoria da infraestrutura da biblioteca central; divulgação, por meio de visualização eletrônica, dos novos livros disponíveis; respeito ao silêncio na biblioteca; informação, com mais clareza, de como funcionam programas como a base de dados; como informar sugestões de compras de livros; dentro do possível, atualização do acervo e realização de um controle mais cuidadoso quanto às rasuras e demais danos às obras; abertura aos domingos; funcionários amigáveis (assim como são a maioria) o que torna a biblioteca um lugar mais agradável.

Analisando-se essas sugestões, percebe-se que o usuário observa como um todo o funcionamento das bibliotecas do SiBUCS. Além dos serviços, é preciso considerar a infraestrutura da biblioteca que deve estar sempre em constante avaliação para oferecer melhorias que facilitem ainda mais o acesso dos usuários. Os profissionais que atuam nas bibliotecas do SiBUCS têm a responsabilidade de desenvolver um bom atendimento para satisfazer as necessidades informacionais dos usuários.

\section{CONSIDERAÇÕES FINAIS}

Estudos de usuários em bibliotecas tornam-se um canal de comunicação entre os usuários e os bibliotecários. De acordo com Figueiredo (1994, p. 7), já citado anteriormente, são estudos de extrema relevância e necessários para que as bibliotecas possam avaliar ou 
reavaliar seus serviços, permitindo que sejam alocados projetos e recursos necessários às demandas da comunidade que frequentam a biblioteca.

Todos os serviços informacionais deverão ser planejados e divulgados a fim de que os usuários possam utilizá-los de forma eficaz e ágil. Com isso, tornam-se necessárias capacitações voltadas aos usuários reais e potenciais sobre as fontes de informações existentes nas bibliotecas.

Sant'Anna e Santos (2004, p. 53) diz que transformar o conhecimento em diferencial competitivo é o grande desafio que se apresenta no novo cenário do mundo atual. Assim, cabe ao profissional bibliotecário atuar como mediador entre os recursos informacionais existentes e os usuários para que, juntos, possam estabelecer sistemáticas necessárias e relevantes para atualização de recursos e divulgação de serviços.

Com a tabulação dos dados, foi possível reconhecer que, embora se tenha todo um processo de divulgação dos serviços do sistema de bibliotecas, alguns usuários desconhecem os recursos informacionais disponíveis, assim como as fontes de informação eletrônicas. Essa pesquisa permitiu que os usuários também conheçam o que as bibliotecas disponibilizam em termos de produtos e serviços.

Quanto ao método utilizado de avaliação, esse auxiliou muito na busca das respostas. Por meio do formulário utilizado na pesquisa, pôde-se obter vantagem quanto à rapidez das respostas, alcançando um grande número de usuários diferenciados na instituição. Dessa forma, o mapeamento das necessidades torna-se mais acessível.

Algumas necessidades foram identificadas por meio do levantamento realizado, tais como: uma maior divulgação dos serviços e produtos das bibliotecas; introduzir os usuários de forma sistemática na utilização das bases de dados; estabelecer políticas de aquisição e assinaturas de livros digitais referentes às necessidades dos usuários; envio de alertas sobre novidades; manuais de procedimentos sobre os recursos eletrônicos, entre outras.

Por meio do estudo apresentado, as bibliotecas da UCS puderam verificar as reais necessidades informacionais dos usuários para poder estabelecer a qualidade de informação disponível, melhorando o sistema, descartando ou atualizando os serviços disponíveis. Ficou evidente, também, que, para promover uma política que desenvolva as diretrizes de uma biblioteca, é necessário conhecer o usuário e a comunidade a que a biblioteca serve. 


\section{REFERÊNCIAS}

CASARIN, Helen de Castro Silva (Org.). Estudos de usuário da informação. Brasília: Thesaurus, 2014.

CUNHA, Vanda Angélica. Questões estratégicas do processo de disseminação da informação em bibliotecas públicas: um estudo de caso. In: CARVALHO, Kátia de; SCHWARZELMÜLLER, Anna Friedericka. O ideal de disseminar: novas perspectivas, outras percepções. Salvador: EDUFBA, 2006, p. 97-114.

FIGUEIREDO, Nice Menezes de. Avaliação de coleções e estudo de usuários. Brasília: Associação dos Bibliotecários do Distrito Federal, 1979.

. Estudos de uso e usuários da informação. Brasília: IBICT, 1994.

GONÇALVES, Ana Lúcia Ferreira. Gestão da informação na perspectiva do usuário: subsídios para uma política em bibliotecas universitárias. Rio de Janeiro: Interciência, 2013.

LEITÃO, Bárbara Júlia Menezello. Avaliação qualitativa e quantitativa numa biblioteca universitária. Rio de Janeiro: Interciência, 2005.

RANGANATHAN, S. R. As cinco leis da biblioteconomia. Brasília: Briquet de Lemos/Livros, 2009.

SANT'ANA, Ricardo César Gonçalves; SANTOS, Plácida Leopoldina Vêntura Amorim da Costa. Transferência de informação: análise de fatores para identificação do valor de unidades de conhecimento registrado. In: VIDOTTI, Silvana Ap. B. Gregorio (coord.). Tecnologia e conteúdos informacionais: abordagens teóricas e práticas. São Paulo: Polis, 2004. p.53-75 (Palavra-Chave, 15)

SANTOS, Izabel Lima dos Santos. A informação e suas leis: um paralelo entre o pensamento de Ranganathan e o de Moody e Walsh. RDBCI: Revista Digital de Biblioteconomia e Ciência da Informação. Campinas, 2015, v. 13, n. 3, p. 469-479. 